\title{
Impact of teleconsultations on the conduct of oral health teams in the Telehealth Brazil Networks Programme
}

\section{Caren Serra BAVARESCO(a) Lisiane HAUSER(b) \\ Ana Estela HADDAD(c) iD \\ Erno HARZHEIM(d) iD}

\footnotetext{
(a) Universidade Luterana do Brasil - Ubra, DDS, Graduate Program in Dentistry, Canoas, RS, Brazil.

(b)TelehealthRS Project, Porto Alegre, RS, Brazil.

(c) Universidade de São Paulo - USP, School of Dentistry, Department of Orthodontics and Pediatric Dentistry, São Paulo, SP, Brazil.

(d) Universidade Federal do Rio Grande do Sul - UFGRS, School of Medicine, Graduate Program in Epidemiology, Porto Alegre, RS, Brazil.
}

Declaration of Interests: The authors certify that they have no commercial or associative interest that represents a conflict of interest in connection with the manuscript.

Corresponding Author:

Caren Serra Bavaresco

E-mail: c_bavaresco@yahoo.com.br

ht1ps://doi.org/10.1590/1807-3107bor-2020.vol34.0011

Submitted: September 11, 2018

Accepted for publication: November 1, 2019

Last revision: January 15, 2020

\begin{abstract}
Telehealth has been applied in the Unified Health System (SUS) as a tool for qualifying professionals and improving the healthcare provided to the population served by the system. The aim of the present study was to evaluate the impact of teleconsultations on the qualifications of the clinical approach of the oral health teams involved in primary health care (PHC) in the state of Rio Grande do Sul under the Telehealth Brazil Networks Programme. The sample population of the study was composed of 285 dentists and 132 oral health assistants belonging to the Family Health Teams. A chi-square test was used to investigate possible associations between the absolute number of teleconsultations performed and several independent variables, namely, gender, age, dental specialty, time since graduation, time working in the Family Health Strategy (FHS), employment status, type of training institution, familiarity with information technology, and work satisfaction at the health facility. The level of significance was $p<0.05$. Use of the oral health teleconsultation service led to a reduction of more than $45 \%$ in the number of referrals to other levels of care. However, no significant association was found between the number of teleconsultations and the independent variables analysed. The use of teleconsultations proved to be a powerful tool for professional training, for increasing the effectiveness of $\mathrm{PHC}$, and for improving the oral healthcare provided.
\end{abstract}

Keywords: Telemedicine; Primary Health Care; Oral Health; Education, Dental.

\section{Introduction}

Brazil is a country with a land mass of continental dimensions characterized by socioeconomic and cultural contrasts, heterogeneous distribution of the healthcare infrastructure, and uneven levels of professional training. These factors, which are associated with access difficulties posed by geographical constraints, lead to differences between the different regions of the country in terms of the access to and quality of the healthcare services provided to the population., ${ }^{1,2}$

The Brazilian healthcare system, known as the Unified Health System (SUS), is public and universally accessible. It is based on providing primary health care (PHC) through the Family Health Strategy (FHS). In 
Brazil, where there are approximately 1.2 dentists per 1,000 inhabitants, dentistry was included in the SUS as of 2003 in both PHC and medium- and high-complexity networks. ${ }^{1}$ The SUS now has 38,000 FHS teams and 22,000 oral health teams in addition to more than 1,000 Dental Specialty Centres (DSCs). The goal of the reorganization of the healthcare model was to expand access to health services by using a comprehensive and longitudinal approach guided by PHC., ${ }^{2,3,4}$ The backbone of the SUS oral health policy includes professional qualification practices for oral health assistants (OHAs), oral health technicians (OHTs) and dentists within the SUS to ensure access to oral healthcare according to the required lines of care and the health conditions of the population. ${ }^{5}$

The Ministry of Health (MH) published a report on a national epidemiological oral health survey conducted in 2010. It revealed a growing demand for dental care with advancing age as well as marked regional inequalities in terms of disease experience. ${ }^{6}$ This situation favours the use of new information and communication technologies (ICTs) aimed at improving professional qualifications and achieving greater equality in the provision of healthcare services. ${ }^{7,89}$

Experiences in several countries have shown that investments in PHC made with the goal of improving physical resources and professional qualifications lead to a significant improvement in the population's health indicators. ${ }^{10,11,12}$ The constant updating of scientific knowledge requires continued professional education to ensure the quality of care. In this context, telehealth is one of the strategies used for solving clinical questions and for scientific updating. ${ }^{13,14}$ It is also a tool for rationalizing the use of funds applied to healthcare and a triggering agent for governmental healthcare actions because it fosters debate among users and professionals in the search for solutions that can be applied to local realities. ${ }^{15}$ In this respect, teledentistry is a field that combines telecommunication technology with dental care and health education. ${ }^{16,17}$

Different initiatives have been undertaken to guide the telehealth process in the country. The MH initially structured and implemented the Telehealth Brazil Programme to cover nine state centres, including the state of Rio Grande do Sul (RS). Later, it expanded the programme to include the entire country, at which time it became known as the Telehealth Brazil Networks. The aim of the TelehealthRS centre was to qualify PHC and to support the FHS through distance education and care processes. ${ }^{1}$ Among its goals are the development of strategies for clinical training, health education, and training for management, planning and assessment skills designed to qualify the FHS teams. This skill enhancement process is guided by a survey of the training needs of the professionals involved so that the content of the programme can be developed to meet the specific needs of the local health teams. ${ }^{2,14,17}$

However, the main activity of the TelehealthRS is to provide prompt and effective answers to the questions posed daily by professionals from FHS teams. These questions may be of a clinical nature or related to the work process, patient flow or management. Specifically regarding oral health, the interaction between an FHS dentist and a teleconsultant dentist, who is a specialist in PHC, takes place through teleconsultations. It should be noted that the provision of this service to professionals from oral health teams is one of the activities that constitute teledentistry. ${ }^{2,14}$

Teleconsultations can be defined as consultations that are conducted and recorded among healthcare workers, professionals and managers using ICT. Teleconsultations are held to provide answers to questions about clinical procedures, health actions and the work process. They can be synchronous (performed in real time) or asynchronous (performed through offline messages). In addition to these services, telehealth centres offer telediagnostic and tele-education strategies as well as a second formative opinion. The latter is defined as a systematized response to frequent questions that are selected according to the criteria of relevance and appropriateness established by SUS guidelines and is based on the best scientific and clinical evidence available. ${ }^{2,16}$

The impact of teleconsultations on the effectiveness of PHC and on the population's health must be evaluated in order for improvements to be made in teledentistry services in general. Therefore, the aim of the present study was to evaluate the impact of oral health teleconsultations on the qualifications 
of the clinical and professional approach of dentists and OHAs involved in PHC in the state of RS, Brazil.

\section{Methodology}

This was a cross-sectional analytical study conducted with a convenience sample. The study sample population consisted of 285 dentists and 132 OHAs and OHTs from Family Health Teams in the state of RS who were members of the TelehealthRS project and who responded to a questionnaire that aimed to monitor and evaluate the teleconsultations. The questionnaire contained personal identification data, professional data and information related to training needs and was administered between December 2007 and October 2012.

The TelehealthRS project is headquartered at the School of Medicine, Federal University of Rio Grande do Sul (UFRGS), and involves the partnership of the UFRGS School of Dentistry, UFRGSSchool of Nursing, Clinical Hospital of Porto Alegre (CHPA), Health Department of the State of Rio Grande do Sul (HD/ RS), and Ministry of Health (MH). Its primary focus is to support FHS teams by providing synchronous and asynchronous teleconsultations, telediagnostics, teleducation and formative second opinions. It is important to note that the strategies developed by the Telehealth centres are in line with Administrative Order no. 2546 issued by the Ministry of Health. ${ }^{2}$

The municipalities to be included in the study were selected according to national guidelines and evaluated regionally by the Rio Grande do Sul State Health Department and the Bipartite Intermanagers Committee. Municipalities with the following characteristics were included:

a. Population of less than 100 thousand inhabitants;

b. Municipal FHS coverage greater than or equal to $70 \%$ of the population;

c. FHS teams with a low turnover of physicians and nurses (up to two replacements per year in the 2005-2007 triennium).

All professionals who participated in the TelehealthRS project were invited to fill out an initial questionnaire that included a personal profile (personal data and familiarity with information technology), a professional profile (undergraduate training, graduate training, professional experience, time working in PHC, time since graduation, employment status, training institution), questions regarding the workplace and work process (work satisfaction at healthcare facility) and questions related to their technical training needs in all dental specialties. Subsequently, the following services were offered to the members of the oral health team: synchronous and asynchronous teleconsultations, webinars, and distance courses.

In the present study, we evaluated the impacts of synchronous and asynchronous teleconsultations. Teleconsultation can be understood as a case discussion performed by one or more professionals who share the responsibility of caring for a patient or solving a clinical question. It can be performed in a synchronous (real time) or asynchronous manner ("store-and-forward"). The answer provided to the clinical question should emphasize the knowledge related to solving the problem posed. Its goal is to expand the technical skills and autonomy of the professional involved in addressing similar cases. ${ }^{2}$

In the present study, the requesting professional used the answer produced during the consultation to evaluate the service provided with regard to the following aspects: his/her satisfaction with the consultation, whether the answer was appropriate to the question asked, whether the professional changed his/her clinical approach after the consultation, and whether the professional decided to refer the patient to other health services and/or another level of healthcare.

Accordingly, the following categorical variables associated with the consultation request were used: satisfaction with the consultation, appropriateness of the answer to the question asked, change of conduct after consultation, and need for referral to other health services and/or another healthcare level. In addition, sociodemographic, professional training and work process variables were included in the analysis.

Data on the personal and professional profiles of the requesting professional were expressed according to their absolute and relative frequencies. Associations between the dependent (number of consultations) and the independent variables (gender, age, dental specialty, time since graduation, time working 
in the FHS, employment status, type of training institution, familiarity with information technology, and satisfaction with work in the health facility) were evaluated using the chi-squared test. Statistical analyses were performed using SPSS 20.0 software (Statistical Package for the Social Sciences) and adopting a significance level of $5 \%$. Only the data of professionals who completed the project's initial questionnaire were included in the assessment of the associations between the participants' professional and personal profiles, totalling 285 dentists and 132 OHA. Professionals who had made two or more requests were included in the assessment of the impact of teleconsultations on the professional approach of dentists and OHAs, totalling 720 participants.

The present study was derived from the study titled "Evaluation of the impact of a TelehealthRS intervention on the characteristics of primary healthcare services / Family Health Strategy in Rio Grande do Sul," a project that was approved by the Research Ethics Committee of the Clinical Hospital of Porto Alegre on January 18, 2008.

\section{Results}

Table 1 shows that there was a predominance of female professionals in both professional categories (97\% among OHAs and 57\% among dentists). Most dentists did not hold a specialist degree in public health, had graduated up to 3 years prior (29.2\%), and had been working in the FHS for less than 1 year (34.1\%). Thirty percent of the OHAs worked in the FHS for periods ranging from 2 to 3 years. Almost half of the professionals in both categories were statutory civil servants and reported that they were satisfied with their work at their healthcare facility $(89.5 \%$ of dentists and $94.7 \%$ of OHAs). It should be noted that only those professionals who completed the study's initial questionnaire were considered in this analysis. Regarding the details of the issues analysed in the teleconsultations, the main topics of the requested teleconsultations are presented in Table 2.

A great discrepancy was noted between the professional categories with regard to their familiarity with information technology: $68.4 \%$ of the dentists reported having a high level of IT knowledge, while
Table 1. Description of the study sample.

\begin{tabular}{|c|c|c|}
\hline \multirow{2}{*}{ Characteristics } & Dentist $(n=285)$ & $\mathrm{OHA} / \mathrm{OHT}(\mathrm{n}=132)$ \\
\hline & n (\%) & n (\%) \\
\hline \multicolumn{3}{|l|}{ Gender } \\
\hline Male & $128(44.9)$ & $4(3)$ \\
\hline Female & $157(55.1)$ & $128(97)$ \\
\hline \multicolumn{3}{|l|}{ Specialty } \\
\hline Public health & $43(27.2)$ & NA \\
\hline Other & $115(72.8)$ & NA \\
\hline \multicolumn{3}{|l|}{ Age } \\
\hline Up to 27 years & $74(26.4)$ & $40(31)$ \\
\hline $28-31$ years & $72(25.7)$ & $16(12.4)$ \\
\hline $32-38$ years & $66(23.6)$ & $25(19.4)$ \\
\hline $39+$ years & $68(24.3)$ & $48(37.2)$ \\
\hline \multicolumn{3}{|l|}{ Time since graduation } \\
\hline Up to 3 years & $83(29.3)$ & NA \\
\hline $4-6$ years & $65(22.9)$ & \\
\hline $8-13$ years & $60(23.2)$ & \\
\hline $14+$ years & $70(24.6)$ & \\
\hline \multicolumn{3}{|l|}{ Time working in the FHS } \\
\hline Up to 1 year & $92(34.0)$ & $24(19.7)$ \\
\hline $2-3$ years & $69(25.5)$ & $37(30.3)$ \\
\hline $3-5$ years & $49(18.1)$ & 23 (18.9) \\
\hline $6+$ years & $60(22.4)$ & $38(31.1)$ \\
\hline \multicolumn{3}{|l|}{ Employment status } \\
\hline Statutory civil servant & $128(46.0)$ & $59(45.0)$ \\
\hline CLT & $64(23.0)$ & $33(25.2)$ \\
\hline Cooperative & $5(1.8)$ & $3(2.3)$ \\
\hline Temporary contract & $62(22.3)$ & $28(21.3)$ \\
\hline Other & $19(6.9)$ & $8(6.2)$ \\
\hline \multicolumn{3}{|l|}{ Type of training institution } \\
\hline Public & $158(55.4)$ & $59(54.1)$ \\
\hline Private & $127(44.6)$ & $50(45.9)$ \\
\hline \multicolumn{3}{|c|}{ Familiarity with information technology } \\
\hline Low & $31(10.9)$ & $60(45.4)$ \\
\hline Intermediate & $59(20.7)$ & $36(27.3)$ \\
\hline High & $195(68.4)$ & $36(27.3)$ \\
\hline \multicolumn{3}{|c|}{ Satisfaction with work at healthcare facility } \\
\hline Satisfied & $250(89.4)$ & $125(94.7)$ \\
\hline Dissatisfied & $29(10.6)$ & $7(5.3)$ \\
\hline
\end{tabular}

FHS: Family health strategy; CLT: employment status according to the Brazilian consolidation of labour laws.

only $27.3 \%$ of the OHAs reported having this level of knowledge.

No statistically significant correlation was observed between the descriptive variables of the study sample and the number of requested 
Table 2. Description of main topics of the teleconsultations requested.

a) Stomatology
b) Oral health for specific populations (diabetic pregnant women,
hypertensive women)
c) Caries prevention
d) Fluoridation
e) Oral surgery
f) Oral health promotion
g) Oral health management

Table 3. Associations between the number of consultations performed only by dentists and the variables presented in Table 1.

\begin{tabular}{|c|c|c|}
\hline Variables & Number of consultations (mean) & $p$-value \\
\hline \multicolumn{3}{|l|}{ Gender } \\
\hline Male & 68.750 & 0.953 \\
\hline Female & 51.613 & \\
\hline \multicolumn{3}{|l|}{ Public health specialist } \\
\hline Yes & 66.875 & 0.052 \\
\hline No & 47.317 & \\
\hline \multicolumn{3}{|l|}{ Age } \\
\hline Up to 27 years & 54.722 & 0.672 \\
\hline $28-31$ years & 78.148 & \\
\hline $32-38$ years & 55.000 & \\
\hline $39+$ years & 50.476 & \\
\hline \multicolumn{3}{|l|}{ Time since graduation } \\
\hline Up to 3 years & 74.878 & 0.513 \\
\hline $4-6$ years & 42.400 & \\
\hline $8-13$ years & 54.783 & \\
\hline $14+$ years & 54.500 & \\
\hline \multicolumn{3}{|c|}{ Time working in the FHS } \\
\hline Up to 1 year & 72.273 & 0.779 \\
\hline $2-3$ years & 47.931 & \\
\hline $3-5$ years & 50.000 & \\
\hline $6+$ years & 55.294 & \\
\hline \multicolumn{3}{|l|}{ Employment status } \\
\hline Statutory and CLT & 68.133 & 0.061 \\
\hline Other & 38.710 & \\
\hline \multicolumn{3}{|c|}{ Type of training institution } \\
\hline Public & 65.806 & 0.708 \\
\hline Private & 50.417 & \\
\hline \multicolumn{3}{|c|}{ Familiarity with information technology } \\
\hline Low & 45.556 & 0.711 \\
\hline Intermediate & 60.000 & \\
\hline High & 60.357 & \\
\hline \multicolumn{3}{|c|}{ Satisfaction with work at healthcare facility } \\
\hline Dissatisfied & 54.286 & 0.37 \\
\hline Satisfied & 60.106 & \\
\hline
\end{tabular}

consultations. However, there was a tendency towards an association between the number of consultations and the professional holding a specialist degree in public health $(\mathrm{p}=0.052$; Table 3$)$.

A total of 680 dentists and $40 \mathrm{OHAs}$ requested two or more teleconsultations from the TelehealthRS project regardless of whether they answered the initial study questionnaire. This cut-off point (two or more requests) was established to exclude dentists who used the teleconsultation service only at the time of the training provided by the TelehealthRS project staff (Table 4). It was observed that $94.4 \%$ of the dental consultation requests were made by

Table 4. Description of the impact of teleconsultations on the professional approach of dentists and oral health assistants who requested two or more consultations.

\begin{tabular}{|c|c|c|}
\hline Variables & $\mathrm{n}$ & $\%$ \\
\hline \multicolumn{3}{|l|}{ Profession $(n=720)$} \\
\hline Dentist & 680 & 94.4 \\
\hline Oral health assistant & 40 & 5.6 \\
\hline \multicolumn{3}{|l|}{ Type of request } \\
\hline Asynchronous & 629 & 87.4 \\
\hline Synchronous & 91 & 12.6 \\
\hline \multicolumn{3}{|l|}{ Request status } \\
\hline Answered & 678 & 94.2 \\
\hline Videoconference required & 21 & 2.9 \\
\hline Specification of question required & 9 & 1.3 \\
\hline Scheduled for videoconference & 1 & 0.1 \\
\hline $\begin{array}{l}\text { Unanswered request due to absent } \\
\text { requesting professional }\end{array}$ & 10 & 1.4 \\
\hline Question unrelated to programme scope & 1 & 0.1 \\
\hline \multicolumn{3}{|c|}{ Satisfaction questionnaire completed by the requesting professional } \\
\hline Yes & 136 & 21.3 \\
\hline No & 501 & 78.7 \\
\hline \multicolumn{3}{|l|}{ Overall satisfaction } \\
\hline Dissatisfied & 11 & 8.1 \\
\hline Satisfied & 124 & 91.9 \\
\hline \multicolumn{3}{|l|}{ Answered the question } \\
\hline Yes & 103 & 77.4 \\
\hline Partially & 30 & 22.6 \\
\hline \multicolumn{3}{|l|}{ Prevented the need for referral } \\
\hline No & 53 & 54.6 \\
\hline Yes & 44 & 45.4 \\
\hline \multicolumn{3}{|l|}{ Changed clinical approach } \\
\hline No & 29 & 35.8 \\
\hline Yes & 52 & 64.2 \\
\hline
\end{tabular}


dentists, $74.9 \%$ of which were text consultations, i.e., asynchronous ones.

Of the professionals, $91.9 \%$ reported being satisfied with the response provided during the teleconsultation. In $76.9 \%$ of the cases, the requesting professional reported having his/her response needs fully met. A change in the clinical approach of the professional occurred in $64.2 \%$ of the cases, and a reduction in the number of referrals to other levels of care occurred in approximately $45 \%$ of the cases.

\section{Discussion}

Telehealth can be seen as an experience that aims to qualify healthcare and, at the same time, rationalize the use of available physical and human resources to improve health care effectiveness and reduce costs. ${ }^{18}$ Thus, the telehealth proposal reinforces the care model adopted in the FHS, which seeks to strengthen the links between the patient, family and health professionals and to value the professionals involved in PHC. ${ }^{1}$ Brazil has more than 200 million inhabitants covered by a national public health system with universal access, and this system includes oral health as a care line under a care network structured according to different levels of care. ${ }^{19}$ The inclusion of dentistry in the SUS, combined with the implementation of the national Telehealth programme, ${ }^{2}$ allowed this study to provide a unique contribution to the literature.

Evidence suggests that the use of teledentistry in PHC can be beneficial in remote areas where access to specialists is limited. ${ }^{16,20,21}$ Implementation of the National Oral Health Policy has increased the population's access to oral health services at the three levels of care through the deployment of the FHS oral health teams, introduction of centres of dental specialties, and hospital dentistry. Nevertheless, the dental care provided by SUS is still heterogeneous. ${ }^{22}$ In this context, teledentistry services can represent a powerful tool for equalizing the supply and quality of services. ${ }^{2}$

A randomized clinical trial conducted in the United Kingdom evaluated the validity of a teledentistry system for screening patients with orthodontic needs. Referral rates, consultation absenteeism, and reduction in the number of inappropriate referrals were evaluated as secondary objectives. The data showed that the teledentistry system was effective regarding the screening of patients with orthodontic needs and reduced the number of unnecessary referrals to reference centres..$^{23}$

A similar impact was found in the present study, which found that the use of asynchronous oral health teleconsultations services was able to reduce the number of referrals for secondary and tertiary care by more than $45 \%$. These data suggest an increase in the effectiveness of PHC mediated by the use of telehealth, which seems to have contributed to qualifying FHS professionals to provide comprehensive care for patients. Similar data were found by Castro Filho, ${ }^{13}$ who observed that the use of telehealth reduced the number of referrals to medical specialties by $50 \%$.

Furthermore, the use of asynchronous strategies can be a cost-effective model of health intervention, as previously described by Elbert et al. ${ }^{24}$ Asynchronous consultations can take place at a time that is convenient for the professional, a feature that may increase the use of this tool. The rules established by the Ministry of Health for the Telehealth programme provide that the requesting professional's question, once received, must be answered within 72 hours. This ensures fluency in the teleconsultation process. Accordingly, the programme has already benefited more than 15,000 health professionals in the country. ${ }^{2,25}$

Another positive aspect associated with asynchronous consultations is a reduction in the embarrassment that some patients with mental disorders may feel during the discussion of their case, as demonstrated by Petcu et al. ${ }^{26}$ In the present study, we observed that the majority of requests involved asynchronous consultations (87.4\%) and the minority involved synchronous ones (12.6\%).

A study conducted by Estai et al. ${ }^{27}$ showed that the use of telehealth services can reduce costs and improve the care provided by professionals, especially in areas without access to health services. McLaren and Kopycka-Kedzierawski ${ }^{28}$ evaluated the diagnostic accuracy of video consultations in 251 paediatric cases of patients residing in rural areas based on the outcomes of referrals made by the professionals involved. The authors concluded that consultations that used video resources were effective in predicting 
the best oral health therapeutic option, especially in the most severe cases. From a cost-effectiveness standpoint, actions that can reduce the aggravation of the oral health status of patients within the system are promising alternatives. Economic evaluations were not performed in the present study; however, it is estimated that a reduced number of referrals, coupled with a sizeable rate of change in the clinical approach observed as a result of the teleconsultations, may have played a key role in healthcare effectiveness, patient flow between care levels, and optimizing the use of public resources.

When considering the use of telehealth by OHAs and OHTs, the limited use of this tool by these professionals is an issue. Daniel and $\operatorname{Kumar}^{29}$ reported positive results obtained by technical-level professionals regarding the identification of dental caries in children aged 4 to 7 years using clinical photographs. In this context, the frequent use of teledentistry by these professionals should be encouraged. Considering the composition of oral health teams in the SUS, which have at least one professional at a technical level, ${ }^{22}$ an extended provision of activities specifically addressing this demographic might contribute substantially to the improvement of oral health promotion and prevention strategies.

Another important point that should be noted is the change in the clinical approach reported by approximately $64 \%$ of the requesting professionals. According to Campos et al., ${ }^{30}$ the Telehealth strategy is a powerful vehicle of permanent education for the FHS. As such, it contributes decisively to discussion about the needs perceived and experienced by professionals and communities while taking into account local specificities.

According to Wen and Tan, ${ }^{31}$ when Telehealth is combined with strategies that qualify healthcare networks, it is no longer just a technological resource supporting the performance of distance activities but rather a resource for widening the scope of action of the care provided. Teledentistry plays an important role in reorganizing oral healthcare networks by qualifying the referrals and the oral healthcare provided at the PHC level.

Possible obstacles to the use of teledentistry are related to professionals' familiarity with technology as well as the availability of equipment and technological inputs. This factor is particularly notable because of the significant percentage $(45 \%)$ of professionals at the technical level who declared that they had a low level of familiarity with the use of information and communication technological resources. Another possible impediment to extending the use of these tools involves the need to provide healthcare workers with a time period allocated by management for case discussion.

Furthermore, the number of professionals who expressed their opinion about the service provided was very limited considering that only $21.4 \%$ of the requesting professionals answered the satisfaction questionnaire. Although the number of professionals who were satisfied with the service reached $91.9 \%$ a value similar to that reported by Marcolino et al..$^{32}$ - there are still biases related to the evaluation of telehealth services that should be studied more closely.

A low rate of utilization of teledentistry services provided to the oral health teams connected to the TelehealthRS project was observed. Haddad et al. ${ }^{7}$ note that it is still necessary to overcome barriers in the work process, in the incorporation of permanent education, and in the management of services to increase the use of telehealth and professionals' demand for teleconsultation services. Similar obstacles to the use of teledentistry have been reported in the literature with regard to issues of technical reliability, diagnostic accuracy, and the cost-benefit ratio of implementing teledentistry centres. ${ }^{27}$

It is important to note that the results of the present study may be related to the characteristics of the TelehealthRS project, which includes services that cover PHC specificities. In telehealth centres that have services available to the secondary or tertiary levels of health care or have different population characteristics, the impact of teleconsultations may achieve results different from those presented in the present study. Thus, comparison of teleconsultation effectiveness in different teledentistry applications should be performed.

\section{Conclusion}

The use of teledentistry has proven to be a powerful tool for professional training, for increasing the 
effectiveness of PHC, and for qualifying the oral healthcare provided. However, it is necessary to train oral health professionals in the use of digital media and modifying the work process in combination with increasing management support since the difficulty in managing the available resources observed in this study may limit access to this tool and, as a result, lessen its impact on the quality of care provided and on oral health indicators.

\section{Acknowledgments}

The authors wish to thank the TelehealthRS project for its technical support, the Municipal Health Departments participating in the TelehealthRS project, the Brazilian Ministry of Health through the national coordination of the Telehealth Networks Programme, and the Pan American Health Organization for its technical cooperation with the Ministry of Health in implementing the programme.

\section{References}

1. Ministério da Saúde (BR). Portaria N².436, de 21 de setembro de 2017. Aprova a Política Nacional de Atenção Básica, estabelecendo a revisão de diretrizes para a organização da Atenção Básica, no âmbito do Sistema Único de Saúde (SUS). Diário Oficial União. 2017 Sep 20.

2. Ministério da Saúde (BR). Portaria N².456, de 27 de outubro de 2011. Redefine e amplia o Programa Telessaúde Brasil, que passa a ser denominado Programa Nacional Telessaúde Brasil Redes (Telessaúde Brasil Redes). Diário Oficial União. 2011 Oct 20.

3. Starfield B. Atenção primária: equilíbrio entre a necessidade de saúde, serviços e tecnologias. Brasília, DF: Ministério da Saúde; 2002.

4. Arantes LJ, Shimizu HE, Merchan-Hamann E. Contribuições e desafios da Estratégia Saúde da Família na Atenção Primária à Saúde no Brasil: revisão da literatura. Cienc Saúde Coletiva 2016 maio;21(5):1499-510. https://doi.org/10.1590/1413-81232015215.19602015

5. Soares CL. Constructing public oral health policies in Brazil: issues for reflection. Braz Oral Res. 2012;26(spel Suppl 1):94-102. https://doi.org/10.1590/S1806-83242012000700014

6. Brasil. SB Brasil 2010: Pesquisa Nacional de Saúde Bucal: resultados. Brasília, DF: Ministério da Saúde; 2012.

7. Haddad $A E$, Bönecker M, Skelton-Macedo MC. Research in the field of health, dentistry, telehealth and teledentistry. Braz Oral Res. 2014;28(1):1-2. https://doi.org/10.1590/1807-3107BOR-2014.vol28.0001

8. Viana FM. Telemedicina: uma ferramenta para ampliar o acesso à assistência em saúde no Brasil [dissertação]. São Paulo: Universidade de São Paulo; 2015.

9. Emami E, Kadoch N, Homayounfar S, Harnagea H, Dupont P, Giraudeau N, et al. Patient satisfaction with E-Oral Health care in rural and remote settings: a systematic review protocol. Syst Rev. 2017 Aug;6(1):174. https://doi.org/10.1186/s13643-017-0550-3

10. Caminal J, Starfield B, Sánchez E, Casanova C, Morales M. The role of primary care in preventing ambulatory care sensitive conditions. Eur J Public Health. 2004 Sep;14(3):246-51. https://doi.org/10.1093/eurpub/14.3.246

11. Starfield B, Shi L, Macinko J. Contribution of primary care to health systems and health. Milbank Q. 2005;83(3):457-502. https://doi.org/10.1111/j.1468-0009.2005.00409.x

12. Santos AM, Giovanella L, Botelho H, Sousa JC. [Organizational challenges in strengthening Primary Health Care in Portugal]. Rev Bras Educ Med. 2015;39(3):359-69. Portuguese. https://doi.org/10.1590/1981-52712015v39n3e01542014

13. Castro Filho ED. Telessaúde no apoio a médicos de atenção primária [dissertação]. Porto Alegre: Universidade Federal do Rio Grande do Sul; 2011.

14. Ministério da Saúde (BR); Universidade Federal do Rio Grande do Sul. Manual de telessaúde para atenção básica. Brasília, DF: Ministério da Saúde; 2012.

15. Eccles A, Atherton H. Automated telephone communication systems may have the potential to play a positive role in healthcare. Evid Based Nurs. 2018 Jan;21(1):23. https://doi.org/10.1136/eb-2017-102707

16. Haddad AE, Skelton-Macedo MC, Abdala V, Bavaresco C, Mengehel D, Abdala CG, et al. Formative second opinion: qualifying health professionals for the unified health system through the Brazilian Telehealth Program. Telemed J E Health. 2015 Feb;21(2):138-42. https://doi.org/10.1089/tmi.2014.0001

17. Roxo-Gonçalves M, Strey JR, Bavaresco CS, Martins MA, Romanini J, Pilz C, et al. Teledentistry: a tool to promote continuing education actions on oral medicine for primary healthcare professionals. Telemed J E Health. 2017 Apr;23(4):327-33. https://doi.org/10.1089/tmj.2016.0101

18. Daniel SJ, Wu L, Kumar S. Teledentistry: a systematic review of clinical outcomes, utilization and costs. J Dent Hyg. 2013 Dec;87(6):345-52.

19. Haddad AE, Silva DG, Monteiro A, Guedes T, Figueiredo AM. Follow up of the legislation advancement along the implementation of the brazilian telehealth programm. J Int Soc Telemed eHealth. 2016;4:e11.

20. Reddy KV. Using teledentistry for providing the specialist access to rural Indians. Indian J Dent Res. 2011 Mar-Apr;22(2):189. https://doi.org/10.4103/0970-9290.84275 
21. Torres-Pereira CC, Morosini IA, Possebon RS, Giovanini AF, Bortoluzzi MC, Leão JC, et al. Teledentistry: distant diagnosis of oral disease using e-mails. Telemed J E Health. 2013 Feb;19(2):117-21. https://doi.org/10.1089/tmi.2012.0087

22. Ministério da Saúde (BR). Diretrizes da política nacional de saúde bucal. Brasília, DF: Ministério da Saúde; 2004.

23. Mandall NA, Qureshi U, Harvey L. Teledentistry for screening new patient orthodontic referrals. Part 2: GDP perception of the referral system. Br Dent J. 2005 Dec;199(11):727-9. https://doi.org/10.1038/sj.bdj.4812969

24. Elbert NJ, Os-Medendorp H, Renselaar W, Ekeland AG, Hakkaart-van Roijen L, Raat H, et al. Effectiveness and cost-effectiveness of ehealth interventions in somatic diseases: a systematic review of systematic reviews and meta-analyses. J Med Internet Res. 2014 Apr;16(4):e110. https://doi.org/10.2196/imir.2790

25. Harzheim E, Gonçalves MR, Umpierre RN, Siqueira ACS, Katz N, Agostinho MR, et al. Telehealth in Rio Grande do Sul, Brazil: bridging the Gaps. Telemed J E Health. 2016 Nov;22(11):938-44. https://doi.org/10.1089/tmj.2015.0210

26. Petcu R, Kimble C, Ologeanu-Taddei R, Bourdon I, Giraudeau N. Assessing patient's perception of oral teleconsultation. Int J Technol Assess Health Care. 2017 Jan;33(2):147-54. https://doi.org/10.1017/S0266462317000319

27. Estai M, Bunt S, Kanagasingam Y, Tennant M. Cost savings from a teledentistry model for school dental screening: an Australian health system perspective. Aust Health Rev. 2018 Sep;42(5):482-90. https://doi.org/10.1071/AH16119

28. McLaren SW, Kopycka-Kedzierawski DT. Compliance with dental treatment recommendations by rural paediatric patients after a live-video teledentistry consultation: A preliminary report. J Telemed Telecare. 2016 Apr;22(3):198-202. https://doi.org/10.1177/1357633X15590705

29. Daniel SJ, Kumar S. Comparison of dental hygienists and dentists: clinical and teledentistry identification of dental caries in children. Int J Dent Hyg. 2017 Nov;15(4):e143-8. https://doi.org/10.1111/idh.12232

30. Campos F, Haddad A, Lung C, Alkmin M, Cury P. The National Telehealth Program in Brazil: an instrument of support for primary health care. Latin Am J Telehealth. 2009;1(1):39-66. https://doi.org/10.32443/2175-2990(2009)11

31. Wen HJ, Tan J. Mapping e-health strategies: thinking outside the traditional healthcare box. Int J Electron Healthc. 2005;1(3):261-76. https://doi.org/10.1504/IJEH.2005.006474

32. Marcolino MS, Alkmim MB, Assis TG, Sousa LA, Ribeiro AL. [Telehealth support for primary health care in remote municipalities in the state of Minas Gerais, Brazil]. Rev Panam Salud Publica. 2014 May-Jun;35(5-6):345-52. Portuguese. 